\title{
Body Image dan Tingkat Kebahagiaan pada Wanita Dewasa Awal
}

\author{
Firma Aulia Maulani ${ }^{1}$ \\ Fakultas Psikologi Universitas Muhammadiyah Malang \\ e-mail: 1firmaaulia22@gmail.com
}

\begin{abstract}
Body image is a form of self-assessment which appears based on societies' perspective. Someone will categorized their self whether they are included or not to the standard of beauty. This condition leads to the satisfaction of their body. However, some experts argue that happiness is a synonym of life satisfaction. It can be concluded that someone will happy when they have been satisfaction to their life. Women in early adulthood have a tendency to focus on their appearance (self-focused). Therefore, they are more focus to take care of their self rather than being involved in social obligation. This current study was conducted to investigate whether body image had an influence or not to the happiness level especially on the women in early adulthood. The total subjects were 150 people. They applied body image scale which is developed by the researcher used body image aspects from cash and happiness scale based on the Subjective Happiness Scale and Satisfaction of Life. The result of this current study showed that there was an influence with $r$ square score $=0,234$. In conclusion, variable $X$ (body image) was influence to variable $Y$ (happiness) with $23,4 \%$ of influence score.
\end{abstract}

KEYWORDS Body image, happiness, woman in early adulthood

CITATION Maulani, F. A. (2019). Body image dan tingkat kebahgaiaan pada wanita dewasa awal. Cognicia, 7, (3), 369-377.

Dewasa awal merupakan masa peralihan dari remaja menuju dewasa, biasanya berada disekitaran usia 18-25 tahun. Pada masa ini biasanya memiliki kecenderungan untuk memikirkan diri sendiri, hal ini dijelaskan oleh Arnet (Santrock 2012) bahwa dewasa awal memiliki lima ciri dan salah satunya adalah self-focused (terfokus pada diri sendiri) yaitu individu memiliki kecenderungan untuk terfokus pada diri sendiri, dalam arti mereka kurang mampu terlibat dalam kewajiban sosial, melakukan tugas dan berkomitmen terhadap orang lain, serta mengakibatkan mereka memiliki otonomi yang besar dalam mengatur kehidupannya. Hal ini tentu saja berlaku terhadap wanita yang menginjak usia dewasa awal, pada dasarnya wanita memiliki kecenderungan untuk tampil cantik dan menarik. Ketika menginjak usia dewasa awal penampilan menjadi sebuah prioritas agar mampu menarik perhatian dari lawan jenis. Melakukan serangkaian perawatan agar tubuh tetap menarik hampir dilakukan oleh setiap wanita, menurut Damanik (2011) mengatakan bahwa wanita sering menyisihkan anggaran untuk perawatan wajah dan tubuh dengan menggunakan kosmetik tradisional maupun modern.

Beberapa orang dapat bahagia karena hal-hal sederhana, namun ada yang menurut mereka hal-hal sederhana terasa biasa saja. Seligman (2002) lebih jauh menjelaskan bahwa untuk mengetahui tingkat kebahagiaan seseorang dapat diukur 
atau diketahui dengan melihat tingkat kepuasaan dirinya. Menurutnya bahwa kebahagian dapat dipengaruhi oleh beberapa hal, yang utama adalah kepuasan hidup (overall satisfaction), lingkugan di luar kontrol diri (circumstances beyond our control) dan tindakan sukarela (voluntary action). Hal ini didukung oleh, Car (Jusmiati 2017) mengemukakan bahwa kebahagiaan itu merupakan kondisi psikologi yang positif, yang ditandai oleh tingginya kepuasan masa lalu, tingginya tingkat emosi positif, dan rendahnya tingkat emosi negatif.

Perasaan bahagia juga dapat dirasakan ketika individu mampu menerima diri sendiri, hal ini didukung oleh pendapat Fordynce (Putra, Arifin \& Hermawati 2016) yang mengatakan bahwa kebahagiaan merupakan perasaan atau pun pengalaman seseorang saat menerima diri dan secara umum agar merasakan perasaan senang. Seperti penelitian yang dilakukukan oleh Tamir, Oishi, Schwartz, \& Kim (2017) yang menggunakan sebanyak 2.324 peserta dari 8 negara yaitu Amerika, Brazil, China, Jerman, Ghana, Israel, Polandia dan Singapura yang menilai bahwa seseorang yang bisa meluapkan emosinya dapat menimbulkan kebahagiaan dan rasa puas dalam dirinya.

Menurut Eddington \& Shuman (2005) terdapat faktor-faktor yang mempengaruhi tingkat kebahagiaan antara lain jenis kelamin dan usia. Penelitian yang dilakukan oleh Chui \& Wong (2018) yang menunjukkan hasil bahwa diantara laki-laki dan perempuan terdapat kesenjangan terkait tingkat kebahagiaan, keduanya menunjukkan bahwa banyak teman dapat membuat kebahagiaan meningkat tetapi tidak membuat hidup menjadi puas. Penelitian yang dilakukan oleh Yue, Jiang, Arjan, Jia, \& Xia (2017) dengan menggunakan 5648 siswa dengan rentang usia 17-28 tahun menghasilkan bahwa wanita lebih mudah merasa bahagia namun juga lebih rentan terhadap gejala depresi dibandingkan dengan laki-laki. Penelitian yang dilakukan Hsieh (2011) menunjukkan bahwa individu yang memiliki usia lebih tua cenderung mudah merasa bahagia dibandingkan individu yang masih muda. Hal ini dapat dikatakan bahwa, wanita mudah merasakan kebahagiaan terutama wanita yang memiliki usia yang cenderung lebih tua.

Munculnya rasa bahagia dapat dipengaruhi oleh faktor internal dan eksternal, kepuasan terhadap diri sendiri tanpa memperhatikan penilaian orang lain terhadap diri sendiri merupakan salah satu faktor munculnya kebahagiaan. Secara tidak langsung perspektif di masyarakat tentang diri sendiri akan berdampak pada munculnya keinginan untuk membandingkan dirinya dengan orang lain, sehingga muncullah sesuatu yang disebut body image. Menurut Cash \& Pruzinsky (Irawan \& Safitri. 2014) memberikan penilaian positif atau negatif pada tubuhnya dapat disebut dengan body image. Wanita memiliki kecenderungan untuk lebih peduli terhadap perubahan fisik daripada laki-laki (Gatti, Ionio, Traficante \& Confalonieri. 2014).

Perubahan-perubahan fisik yang dialami mengahasilkan persepsi yang berubahberubah, dan hal ini secara tidak langsung akan membangun pola pikir bagaimana definisi cantik menurut diri sendiri. Hal ini sejalan dengan menurut Qaisy (2016) bahwa pada awalnya, wanita hanya kurang puas pada bagian tubuh tertentu yang kemudian membuat mereka mengalihkan fokus ke orang lain, biasanya mereka berfokus pada berat badan, ukuran payudara, jerawat dan bentuk tubuh. Ketika seseorang membandingkan diri dengan orang lain maka secara tidak langsung akan 
muncul standart tersendiri dan membuat orang tersebut akan terlihat cantik ketika mampu mencapai standart yang telah dibangun.

Penelitian selanjutnya mengungkap faktor yang mempengaruhi body image salah satunya adalah self-esteem. Penelitian yang mengungkap pengaruh body image terhadap self-esteem sudah sering dilakukan salah satunya yang dilakukan oleh Johry dan Srivastava (2015), mereka mengambil sampel 250 mahasiswi Universitas Allahabad untuk mengetahui hubungan antara body image dan self esteem, hasil menunjukkan bahwa self-esteem menjadi faktor penting dalam pembentukan body image. Wanita yang memiliki self esteem yang rendah semakin tidak puas terhadap bentuk tubuhnya, dan penelitian ini juga mengungkap bahwa peran orang tua dan kekasih meningkatkan ketidakpuasan terhadap bentuk tubuh.

Selain faktor internal seperti self esteem peran lingkungan juga mempengaruhi persepsi diri mengenai body image seseorang. Dan penelitian lain yang dilakukan oleh Pop (2016) yang mengambil sampel dari Universitas Romania tentang persepsi lingkungan tentang body image memberikan hasil bahwa sebanyak $79 \%$ tidak puas dengan penampilan fisik mereka sehingga hal tersebut berpengaruh pada rendahnya self-esteem mereka.

Berdasarkan penelitian-penelitian tersebut, dapat disimpulkan bahwa wanita cenderung memiliki persepsi diri terhadap body image yang dipengaruhi oleh selfesteem dan peran lingkungan. Kemudian, faktor-faktor yang mempengaruhi kebahagiaan salah satunya adalah jenis kelamin dan diungkap bahwa wanita lebih mudah merasa bahagia tetapi juga lebih mudah merasa depresi karena pengalaman negatif. Hal ini didukung oleh penelitian yang mengungkap adakah hubungan antara body image dan kebahagiaan dilakukan oleh Swami, Stieger, Tran \& Voracek (2014) pada wanita barat dan hasilnya adalah sebanyak $89 \%$ wanita menunjukkan ketidakpuasan dengan bentuk tubuhnya dengan mayoritas $84,1 \%$ ingin menjadi kurus dan menunjukkan korelasi positif dengan kebahagian.

Kebahagiaan dapat muncul ketika individu sudah merasa puas dengan dirinya sedangkan body image tercipta dikarenakan individu kurang puas dengan bentuk tubuhnya dan mengukur sesuai standart yang dibuat oleh lingkungan, sedangkan pada dewasa awal cenderung untuk berfokus pada diri sendiri terutama pada penampilan. Berdasarkan hal tersebut peneliti ingin melihat apakah ada pengaruh body image terhadap tingkat kebahagiaan seseorang yang menginjak dewasa awal, khususnya perempuan melihat hasil penelitian sendiri wanita lebih fokus pada perubahan dirinya.

Selama ini body image selalu dikaitkan dengan self-esteem dan kepercayaan diri saja. Penelitian terakhir dilakukan pada tahun 2014 yang dilakukan oleh Swami, Stieger, Tran \& Voracek dan yang menggunakan mayoritas wanita barat tidak dapat digeneralisasikan. Oleh karena itu peneliti ingin meneliti terkait tentang Body Image dan Tingkat Kebahagiaan pada Wanita Dewasa Awal.

Penelitian ini dilakukan untuk mengetahui apakah ada pengaruh body image terhadap tingkat kebahagiaan pada wanita dewasa awal. Mengingat bahwa dewasa awal sendiri lebih berfokus pada dirinya dan penelitian sebelumnya juga menyebutkan bahwa wanita lebih peduli terhadap perubahan dirinya dibandingkan dengan lak-laki. 
Berdasarkan pada tujuan tersebut, memiliki manfaat baik secara teoritis maupun secara praktis. Penelitian ini diharapkan mampu intuk menambah wawasan ilmu terkait penelitian yang dilakukan, serta dapat menambah informasi dan menyumbangkan pemikiran terkait penelitian yang dilakukan. Dan diharapkan bagi penelitian selanjutnya agar lebih mengeneralisaikan penelitian ini dengan subjek yang lebih bervariasi

\section{METODE}

Penelitian ini menggunakan penelitian kuantitatif dengan pendekatan asosiatif hubungan korelasi. Menurut Sugiyono (2017) pendekatan assosiatif adalah suatu rumusan masalah penelitian yang bersifat menanyakan hubungan antara dua variabel atau lebih, terdapat tiga bentuk hubungan salah satunya adalah korelasi. Menurut Sugiyono (2017) korelasi adalah mengetahui adanya pengaruh atau hubungan antara dua variabel dengan cara mengumpulkan data. Dalam penelitian ini menganalisa tentang pengaruh body image terhadap tingkat kebahagiaan pada wanita dewasa awal.

Adapun karakteristik subjek penelitian adalah seseorang berjenis kelamin wanita dengan usia 18-25 tahun. Teknik sampling yang digunakan adalah kuota sampling, dimana menurut Sugiyono (2017) teknik ini merupkan teknik menentukan sampel dari populasi yang mempunyai ciri-ciri tertentu sampai jumlah (kuota) yang diinginkan. Oleh karena itu jumlah sampel yang akan digunakan sebanyak 150 sampel dimana menurut Sugiyono (2017) ukuran sampel yang layak digunakan adalah 30 sampai 500 sampel, dengan karakteristik subjek yang sudah ditentukan.

Pengumpulan data menggunakan kuisioner atau angket dimana menurut Sugiyono (2017) kuisioner merupakan teknik pengumpulan data pernyataan atau pertanyaan tertulis kepada responden untuk dijawab. Kusioner berisi tentang variabel $(\mathrm{X})$ atau variabel bebas pada penelitian ini adalah body image. Body image adalah perasaan kurang puas terhadap bentuk tubuh yang muncul berdasarkan perspektif lingkungan. Dan variabel $(\mathrm{Y})$ atau variabel terikat pada penelitian ini adalah kebahagiaan. Kebahagiaan adalah perasaan positif dalam diri individu dan dapat dilihat berdasarkan kepuasan dalam dirinya.

Kedua kuisioner tersebut dimodifikasi menggunakan model skala likert, menurut Sugiyono (2017) model skala likert digunakan untuk mengukur sikap atau pandangan terhadap suatu fenomena yang telah ditetapkan secara spesifik oleh peneliti dengan rentang penilain sangat positif dan sangat negatif. Fenomena yang akan diukur adalah pengaruh body image terhadap tingkat kebahagiaan dimana peneliti mengukur body image menggunakan skala body image yang dikembangkan oleh peneliti menggunakan aspek-aspek body image dari Cash dengan nilai reliabilitas 0,713. Aspek-aspek yang diungkap dalam skala ini yaitu Appearance evaluation, Appearance orientation, Body area satisfaction, Overweight preoccupation, Self-classified weight dengan menggunakan rentangan pilihan 1-5 dengan kategori STS = Sangat Tidak Setuju, TS = Tidak Setuju, KS = Kurang Setuju, S = Setuju, dan SS = Sangat Setuju.

Peneliti mengukur kebahagiaan menggunakan skala kebahagian yang disesuaikan berdasarkan Subjective Happiness Scale yang dibuat oleh Sonja Lyumbormirksy untuk mengukur komponen kebahagiaan secara keseluruhan dan Satisfaction of Life yang disusun oleh E. Diener untuk mengukur kebahagiaan 
berdasarkan kepuasan masa lalunya, kemudian digunakan oleh Maharani (2015) dengan nilai reliabilitas 0,954. Aspek-aspek yang diungkap adalah aspek kognitif dan afektif dengan menggunakan rentang pilihan 1-5 dengan kategori STS = Sangat Tidak Setuju, TS = Tidak Setuju, KS = Kurang Setuju, S = Setuju, dan SS = Sangat Setuju .

Prosedur dalam penelitian ini terdiri dari tiga tahap, yaitu persiapan, pelaksanaan dan analisa data. Tahap persiapan terdiri dari mencari fenomena, menyusun proposal penelitian, merumuskan rumusan masalah dan mempersiapkan instrumen berupa skala body image dan kebahagiaan. Setelah itu peneliti melakukan try out untuk mendapatkan data yang valid dan reliabel. Sampel dalam penelitian ini adalah wanita dewasa awal usia 18-25. Peneliti mengambil sampel ini dengan mempertimbangkan beberapa pertimbangan yaitu sampel mudah dijangkau dan sampel sesuai dengan kriteria subjek yang diinginkan.

Tahap kedua yaitu pelaksanaan penelitian dengan menyebar skala kepada wanita dewasa awal usia 18-25 tahun. Penyebaran skala dilakukan dengan cara peneliti sudah menentukan kriteria subjek terlebih dahulu, kemudian peneliti mendatangi subjek dan menjelaskan kriteria subjek penelitian, apabila subjek memiliki kriteria yang diinginkan oleh peneliti makapeneliti akan memberikan dua skala sekaligus untuk diisi, sebelum subjek mengisi skala, peneliti terlebih dahulu memberikan pengantar yang bertujuan untuk memastikan bahwa subjek tidak salah dalam proses pengerjaan.

Selanjutnya adalah entry data, dan proses analisa data, dalam proses ini peneliti menggunakan software perhitungan statistik SPSS for windows versi 22 menggunakan analisis regresi, menurut Sugiyono (2017) analisi ini digunakan untuk melakukan prediksi bagaimana perubahan nilai variabel dependen $(Y)$ bila nilai variabel independen $(X)$ dinaikkan atau diturunkan. Teknik statistik linier sederhana juga didasarkan pada hubungan fungsional ataupun kausal satu variabel independen dengan satu variabel dependen. Penyusunan hasil penelitian berdasarkan analisa yang diperoleh, membahas dan menyimpulkan hasil penelitian.

\section{HASIL}

Berdasarkan uji Kolmogorov-smirnov, data dikatakan normal apabila nilai signifikan di atas 0,05. Hasil uji normalitas menunjukkan bahwa kedua variabel dikatakan normal karena nilai signifikan variabel $X$ (body image) sebesar 0,170 ( $p>0,05)$ dan nilai signifikan variabel Y (kebahagiaan) sebesar 0,665 ( $p>0,05)$.

Tabel 1. Uji T-Score

\begin{tabular}{ccccc}
\hline Variabel & Kategori & & Frekuensi & Persentase \\
\hline Body Image & Tinggi & $>50$ & 81 & $54 \%$ \\
& Rendah & $\leq 50$ & 69 & $46 \%$ \\
Kebahagaiaan & Tinggi & $>50$ & 76 & $50,7 \%$ \\
& Rendah & $\leq 50$ & 74 & $49,3 \%$ \\
\hline
\end{tabular}

Tabel di atas menunjukkan data variabel body image dan kebahagiaan dibagi menjadi dua kategori data yaitu kategori tinggi dan rendah. Untuk varibael body image 
kategori tinggi sebanyak 81 orang (54\%) dan kategori rendah sebanyak 69 orang (46\%), untuk variabel kebahagiaan kategori tinggi sebanyak 76 orang $(50,7 \%)$ dan kategori rendah sebanyak 74 orang (49\%).

Untuk mengetahui ada atau tidaknya pengaruh variabel X (body image) terhadap variabel Y (kebahagiaan), mengetahui korelasi positif atau negatif, serta mengetahui seberapa besar pengaruh variabel X (body image) terhadap variabel Y (kebahagiaan) maka dilakukan uji regresi liner. Berikut adalah hasil analisis yang didapatkan:

Tabel 2. Regresi Linier

\begin{tabular}{cccc}
\hline Model & R & R Square & Sig \\
\hline 1 & $.493^{\mathrm{a}}$ & .243 & $.000^{\mathrm{b}}$ \\
\hline
\end{tabular}

Menunjukkan bahwa nilai signifikan (sig) variabel sebesar $0,000(\mathrm{p}<0,05)$ hal ini menjelaskan bahwa adanya pengaruh variabel $\mathrm{X}$ (body image) terhadap variabel $\mathrm{Y}$ (kebahagiaan). Selain itu nilai $\mathrm{r}$ square didapatkan adalah 0.243 , yang berarti bahwa variabel X (body image) memberikan pengaruh sebesar $24,3 \%$ terhadap variabel $\mathrm{Y}$ (kebahagiaan). Hal ini menunjukkan bahwa terdapat pengaruh yang cukup besar antara body image terhadap tingkat kebahagiaan seseorang.

\section{DISKUSI}

Munculnya body image terjadi karena perspektif masyarakat yang menciptakan standart bentuk tubuh ideal, individu yang menilai bentuk tubuhnya cenderung akan mempengaruhi kepuasan terhadap diri sendiri, semakin individu merasa puas pada diri sendiri maka akan merasa bahagia. Hasil dari penelitian ini menunjukkan bahwa hipotesa diterima, yaitu terdapat pengaruh antara body image terhadap tingkat kebahagiaan pada wanita dewasa awal dengan pengaruh sebesar $24,3 \%$ dengan arah yang positif. Hal ini menunjukkan bahwa kepuasan seseorang terhadap bentuk tubuhnya berpengaruh cukup besar terhadap tingkat kebahagiaan seseorang. Maka dijelaskan bahwa semakin puas terhadap bentuk tubuhnya maka akan semakin tinggi tingkat kebahagiaan orang tersebut terutama pada wanita. Begitu juga sebaliknya, semakin seseorang merasa kurang puas terhadap bentuk tubuhnya maka akan semakin rendah tingkat kebahagiaannya.

Pendapat Cash (2012) menjelaskan bahwa body image merupakan penilaian menyeluruh individu terhadap bentuk tubuhnya, serta tingkat kepuasan individu terhadap penampilannya. Seligman (2002) yang menjelaskan bahwa untuk mengetahui tingkat kebahagiaan orang lain dapat dilihat berdasarkan kepuasan terhadap dirinya. Dalam hal ini menunjukkan bahwa semakin seseorang merasa kurang puas terhadap bentuk tubuhnya maka akan semakin rendah tingkat kebahagiaan seseorang. Maka menunjukkan bahwa munculnya perspektif lingkungan tentang body image yang muncul akan mempengaruhi kepuasan terhadap bentuk tubuhnya, sehingga kepuasan tersebut akan berpengaruh terhadap kebahagiaan individu tersebut. Dimana telah dijelaskan bahwa cara melihat kebahagiaan seseorang dapat dilihat dari bagaimana kepuasan terhadap dirinya. Hal ini didukung oleh penelitian yang dilakukan sebelumnya yang dilakukan oleh Swami, Stieger, Tran \& Voracek (2014) dengan 
menggunakan subjek wanita barat dan hasilnya menunjukkan bahwa sebanyak $89 \%$ wanita menunjukkan ketidakpuasan terhadap bentuk tubuhnya dengan mayoritas $84,1 \%$ ingin memiliki berat badan yang ideal dan menunjukkan korelasi yang positif dengan kebahagiaan.

Penelitian ini menggunakan responden berjenis kelamin wanita dengan rentang usia 18-25 tahun dan hasil yang didapatkan dalam penelitian ini dalam kategorisasi variabel kebahagiaan sebanyak 76 orang $(50,7 \%)$ memiliki tingkat kebahagiaan yang tinggi sedangkan 74 orang (49\%) memiliki tingkat kebahagiaan yang rendah. Data ini menunjukkan bahwa hampir rata-rata dari responden memiliki kebahagiaan yang tinggi, maka dapat dikatakan bahwa wanita pada usia tersebut memiliki tingkat kebahagiaan yang tinggi. Penelitian yang dilakukan Yue, Jiang, Arjan, Jia \& Xia (2017) dengan menggunakan 5.4648 siswa dengan rentang usia 17-28 tahun menunjukkan bahwa wanita lebih mudah merasakan bahagia. Hal ini sejalan dengan penelitian yang dilakukan Hsieh (2011) yang menunjukkan bahwa individu yang lebih tua cenderung mudah merasa bahagia dibandingkan dengan individu yang masih muda.

Dalam kategorisasi variabel body image data menunjukkan bahwa sebanyak 81 orang (54\%) memiliki body image yang tinggi, sedangkan sebanyak 69 orang (46\%) memiliki body image yang rendah. Dapat dikatakan bahwa sebagian besar responden memiliki kepuasan yang tinggi terhadap bentuk tubuhnya, sedangkan sebagian responden memiliki ketidakpuasan yang rendah terhadap bentuk tubuhnya. Responden yang memiliki body image yang rendah maka akan merasa tidak puas terhadap bentuk tubuhnya, ketidakpuasan tersebut akan membuat munculnya keinginan merubah atau membandingkan bentuk tubuhnya dengan orang lain. Hal ini sejalan dengan Qaisy (2016) pada awalnya, wanita hanya kurang puas pada bagian tubuh tertentu yang kemudian membuat mereka mengalihkan fokus ke orang lain, biasanya mereka berfokus pada berat badan, ukuran payudara, jerawat dan bentuk tubuh mereka.

Meskipun penelitian ini menujukkan adanya pengaruh antara body image terhadap tingkat kebahagiaan seseorang serta memiliki korelasi yang positif, penelitian ini juga memiliki beberapa kelemahan. Penelitian yang dilakukan hanya menunjuk pada satu faktor, sedangkan terdapat beberapa faktor yang bisa saja mempengaruhi tingkat kebahagiaan individu.

\section{SIMPULAN DAN IMPLIKASI}

Berdasarkan hasil penelitian ditemukan bahwa ada pengaruh body image terhadap tingkat kebahagiaan pada wanita dewasa awal berpengaruh sebesar 24,3\% dengan arah yang positif. Maka dapat disimpulkan bahwa body image berpengaruh cukup besar pada kebahagiaan terutama pada wanita dewasa awal semakin seseorang merasa puas dengan bentuk tubuhnya maka akan semakin bahagia orang tersebut, begitu juga sebaliknya semakin seseorang merasa kurang puas dengan bentuk tubuhnya semakin tidak bahagia orang tersebut.

Implikasi dari penelitian ini adalah agar para responden lebih menghargai diri sendiri, tidak membandingkan diri dengan orang lain maupun perspektif masyarakat, dan mengembangkan potensi-potensi yang lain dalam dirinya. Meskipun standart kecantikan sering berubah sewaktu-waktu dan tidak sedikit dari lingkungan sosial 
mengkritik penampilan atau bentuk tubuh. Salah satu alternatif agar tidak mudah membandingkan diri sendiri dengan orang lain serta tidak terpengaruh dengan kritikan orang lain adalah dengan menanamkan pemikiran positif pada diri sendiri bahwa setiap orang memiliki kelebihan maupun kekurangan masing-masing. Dengan harapan agar individu tersebut tidak hanya berfokus pada bentuk tubuh, melainkan mengembangkan kelebihan-kelebihan yang lain agar lebih dihargai oleh lingkungan.

Hasil dari penelitian ini diharapkan dapat membantu menambah informasi bahwa body image juga mempengaruhi kebahagiaan. Dalam penelitian ini masih terdapat banyak kekurangan, diantaranya peneliti yang berfokus pada satu faktor saja sedangkan masih banyak faktor lain yang bisa diukur. Oleh karena itu peneliti berharap agar penelitian selanjutnya dapat mengungkap faktor lain yang mempengaruhi tingkat kebahagiaan seseorang.

\section{REFERENSI}

Andiyanti, A. D. W. (2016). Hubungan antara body image dengan kepercayaan diri siswa kelas X di SMA negeri 2 bantul. E-journal bimbingan dan konseling. Edisi 4 tahun 2016

Bahrami, A. (2017). The effect of happiness on various aspect of parenting and positive parenting. International Journal Psychology and Behavioral. Vol. 4, Issue 1

Cash, T. F. (2012). Cognitive-behavioral perspectives on body image. Encyclopedia of Body Image and Human Appearance. Academic Press: Elsevier

Chui, W. H. \& Wong M. Y. H. (2015). Gender differences in happiness and life satisfaction among adolescents in hong kong: relationship and self-Concept. Social Indicators Research. 125:1035-1051

Damanik, B. T. (2011). Persepsi remaja putri di kota ambon tentang risiko terpapar kosmetik berbahaya dalam memilih dan mengunakan kosmetik. Berita Kedokteran Masyarakat. Vol. 27 No. 1

Eddington, N. \& Shuman, R. (2005). Subjective well being (happiness). Continuing Psychology Education: 6 Continuing Education Hours. San Diego

Gatti E. , Ionio C., Traficante D., \& Confalonieri E. (2014). " I like my body; therefore, i like myself": how body image influence self-esteem a cross-sectional study on italian adolescents. Europe's Journal of Psychology. Vol 10(2) 301-317

Harijanto, J. \& Setiawan J. L. (2016). Hubungan antara dukungan sosial dan kebahagiaan pada mahasiswa perantauan di surabaya. Skripsi Psikologi. Universitas Ciputra Surabaya

Hsieh, C. M. (2011). Money and happiness: does age make difference. Ageing \& Society. Vol. 31 Issue 08 November 2011

Husna, N. L. (2013). Hubungan antara body image dengan perilaku diet (penelitian pada wanita di sanggar senam RITA pati). Skripsi Psikologi. Universitas Negeri Semarang

Hurlock, E. B. (2013). Psikologi perkembangan: suatu pendekatan sepanjang rentang kehidupan. Jakarta: Erlangga

Ifdil, Denich A. U., \& Ilyas A. (2017). Hubungan body image dengan kepercayaan diri remaja putri. Jurnal kajian bimbingan dan konseling. 2(3), 2017, 107-113

Irawan, D. S., \& Safitri. (2014). Hubungan antara body image dan perilaku diet mahasiswi esa unggul. Jurnal Psikologi. Vol 12 Nomor 1, Juni 2014

Johry, A., \& Srivastava, S. (2015). Relationship between body image and self-esteem among college going girls. Asian Journal of Home Science. Volume 10, Issue 1, June 2015, 208-214

Jusmiati. (2017). Konsep kebahagiaan martin seligman: sebuah penelitian awal. Jurnal Psikologi. Vol. 13 No. 2 Desember 2017: 359-374

Linley, P. A., \& Joseph, S. (2004). Positife Psychology in practice. United State of America 
Maharani, D. (2015). Tingkat kebahagiaan (happiness) pada mahasiswa fakultas ilmu pendidikan universitas negeri yogyakarta. Skripsi Psikologi Pendidikan dan Bimbingan. Universitas Negeri Yogyakarta

Pop, C. L. (2016). Self-esteem and body Image perception in a sampel of student university. Eurasian Journal of Educational Research. Issue 64, 2016, 31-44

Putra, B. S., Arifin. B. S., \& Hermawati N. (2016). Mortality salience dengan kebahagiaan pada masa dewasa awal. Jurnal Ilmiah Psikologi Terapan. Vol. 04, No.01, Januari 2016

Qaisy, L. M. (2016). Body image and self-esteem among isra' university students. British Journal of Educational. Vol.4, No.8, pp.63-71

Rozika, L. A., \& Ramdhani N. (2016). Hubungan antara harga diri dan body image dengan online self-presentation pada pengguna instagram. Gadjah Mada Journal of Psychology. Vol. 2 No. 3 2016: 172-183

Rusdiana, I. Konsep Authentic happiness pada Remaja dalam Teori Myers. Jurnal Kependidikan Dasar Islam Berbasis Sains. Vol. 2 No. 1, tahun 2017

Santrock, J. W. (2013). Life-Span Development (Jilid 2). Jakarta:Erlangga

Seligman, M. E. P. (2002). Beyond authentic happiness. Ocred and Compacted by Dainstanthit

Sharma, S. K., \& Sharma, O. P. (2016). Spirituality leads to happiness: a correlative study. The International Journal of Indian Psychology. Vol. 3, Issue 2, No. 10

Sugiyono, (2017). Metode penelitian kuantitatif, kualitatif, dan RED. Bandung. Alfa Beta

Smolak, L. E., \& Thompson, J. (2009). Body image, eating disorders and obesity in youth: assessment, prevention, and treatment. American Psychology Association

Swami, V., Stieger S., Tran U., S., \& Voracek M. (2014). Associations bestween women's body image and happiness: results of the youbeauty.com body image survey (YIBS). Research Paper. 16:705-718

Tamir, M., Oishi S., Schwartz S., H., \& Kim M. Y. (2017). The secret to happiness: feeling good or feeling right?. Journal Of Experimental: General. Vol. 146, No. 10, 1448-1459

Veenhouven, R. (1984). Condition of happiness. Holland: D. Riedel Publishing Company.

Yue, D. X., Jiang F., Arjan H. N., Jia H., \& Xia L. S. (2017). How gender matters for happiness: a serial study of college students in china. International Journal of: Psychology and Behavior Analysis. Vol. 3, 2017, 122 